Accepted for publication in Information Polity published by IOS Press. The final published version is available at: https://doi.org/10.3233/IP-170065

\title{
Smart Governance: Opportunities for Technologically-mediated Citizen Co-production
}

C. William R. Webster and Charles Leleux, Stirling Management School, University of Stirling

\section{Abstract}

Citizens increasingly contribute directly to the evolution of sustainable cities, in particular where new Information and Communication Technologies (ICTs) promise to transform urban governance into 'Smart city governance' and where ICTs are integrated in strategies for citizen participation and the co-production of public services and policy. This article provides a multidisciplinary understanding of Smart city governance, including new insights around the opportunities for citizen engagement in the co-production of service-delivery and decisionmaking. Using findings from a review of Smart cities literature and practice, the article aims to establish the breadth of Smart city initiatives which emphasise citizen participation and the realities of delivering such initiatives in complex city environments. Emphasising the emerging role of the technologically 'empowered' citizen, a new conceptual model is presented, where mutual trust, shared understanding and new opportunities for co-production emerge in an environment mediated by new technology - this form of Smart governance is referred to here as 'technologically-mediated municipal reciprocity'.

Keywords: Smart governance, citizen co-production, technologically-mediated municipal reciprocity, egovernance, eGovernment (eGov), Information and Communication Technologies (ICTs), sustainability. 


\section{Smart Governance: Opportunities for Technologically-mediated Citizen Co-production}

\section{Introduction}

There is a growing body of knowledge and practice around the transformative potential of new Information and Communication Technologies (ICTs) in 'Smart city' environments [19, 58]. There is usually a focus on digitally enhanced public services and the co-production of services and policy [24, 40, 45]. The emphasis here is to utilise the potential offered by new technology to realise more efficient public services and to inform the public policy process so that better public decision-making takes place. More recently, there has been an emerging interest in using the same Smart city technologies to engage citizens and to allow them to participate directly in co-production of services and policy [17]. This, it is argued, will allow them to exert influence and control over public service provision and to ensure that services are delivered in their interests [54]. The term 'Smart governance' is used to capture these new technologically mediated governance arrangements and practices [53]. Traditional eGovernment (eGov) studies have tended to view citizen engagement through a normative perspective, that is, the adoption of Information and Communication Technologies (ICTs) is a 'good thing' and is a desirable activity for governments and citizens to actively engage in [63, 74]. In reality, citizen engagement is more nuanced, more variable, and shaped by a variety of contexts and situations, with tensions emerging where citizens and governments do not have a shared interest in working together [15].

New ICTs offer the promise of transforming urban governance into 'Smart city governance' when technologies are integrated in strategies for citizen participation and coproduction. This can take the form of online voting and consultation, often referred to as eParticipation [39], or more innovative mechanisms using new social media, incentivisation 
and gamification [80]. Here, new ICTs give citizens a voice and an opportunity to take part in processes that define the future delivery of services. Their direct influence in the policy process means that outcomes are 'co-produced', in that they are emerging from an interaction with the state, and mediated by new ICTs. Further to this, citizens are increasingly consuming public services via new ICTs through a raft of practices and technologies usually referred to as eGov [47].

In this article, we explore the role of citizen engagement in processes of Smart governance, with the intention of identifying emergent themes and the key elements of technologically mediated Smart governance. It is evident, that there is a lack of knowledge about processes surrounding eParticipation and the incentivisation of citizens in the coproduction of services and policy via ICTs. In order to comprehend how and why citizens are incentivised and motivated in this process we bring forward a conceptual approach referred to as 'technologically-mediated municipal reciprocity'. This approach points to the requirements necessary for mutual benefits and reciprocal outcomes to be realised by both citizens and municipalities in an environment where relations are mediated by new technologies, and represents a 'new take' on Smart city governance. The 'technologicallymediated municipal reciprocity' model is presented in Section 4 and can be used by policymakers and practitioners to understand Smart governance 'ingredients' and help guide future research in this area. Reciprocity outcomes can be viewed in a tangible sense, for example where citizens can offer suggestions for municipal investment in local infrastructure improvements, and also intangibly where the benefits of eParticipation might simply be closer working relations between both parties, and the creation of mutual trust. Developments in new ICTs mean that alternative methods of participation and co-production now offer more possibilities for the redistribution of power to citizens than originally envisaged in Arnstein's 
[4] seminal model on participation. Issues relating to representativeness, power and control remain, and they have become more opaque due to the diversity and number of actors involved in these processes of participation, and their respective motivations for engagement [30]. Examples of Smart city mechanisms for participating are varied and include: hackathons, living labs, fablabs, Smart urban labs, citizen dashboards, maker spaces, Smart citizens' labs, gamification concepts, and open datasets. A brief description of each of these examples is provided in Section 3.

Citizens have become increasingly attuned to using ICTs in their everyday lives, for communicating with each other and service providers, to undertake transactions, to request services, or to provide feedback on services, often instantaneously, and public services are not immune to these transformational changes in society [81]. It is often argued, that public services need to embrace the opportunities that new ICTs offer as a means of improving their engagement levels with citizens [13]. There is also a pressing need to understand better, how citizen participation works, who it includes or excludes, who benefits and loses, the strategic ambitions of each service provider, and to what extent the technology is driving engagement [46]. Distribution of power can be influenced by the design and use of technology and through the capacity to interpret data, although unless there is an understanding of how data is produced and used, the results could be more illusory than material [55].

The extent to which citizens are able to exert influence over service delivery matters is questioned by a number of authors [11, 33, 41]. Hastings et al. [33], point to the differential levels of participation by certain groups in society, arguing that greater influence is often exerted in 'more bourgeois areas' where the citizens are better tuned-in to local issues, rather than in less affluent areas, where citizen participation levels are much weaker. Pestoff [72] argues, that the introduction of co-production initiatives, is being driven, in part, by a desire 
to reduce costs, but crucially identifies that the conditions necessary for successful and sustainable co-production are dependent upon changing behaviours of both public officials and citizens. In its most simplistic form, co-production may well be regarded as a diluted form of eGov, involving purely transactional activities where citizens may have been asked to comment only on the format or their preference for using this type of service, rather than being asked to contribute ideas which could genuinely influence the content or structure of service delivery. Meijer and Bolívar [52] contend that Smart city governance is not just a technological issue, but rather one which involves a complex process of institutional change, and that we should acknowledge the political nature and appealing visions of sociotechnological governance.

The remainder of the article is split into five main sections. The next section, Section 2 , sets out the methods underpinning this research, with specific reference to the international SmartGov research project. Following this, Section 3 explores the concept of Smart city governance in more detail, and sets out a list of mechanisms which facilitate Smart city governance, engagement and participation. Section 4 presents the 'technologically-mediated municipal reciprocity' approach to understanding Smart city governance. This is followed by Section 5, which offers concluding comments and discussion.

The underlying purpose of the article is to identify the core elements of Smart city governance, and how these elements interact and relate to one another in a process that is perceived to be mutually beneficial and provide positive societal outcomes. The new conceptual approach based on reciprocity and technology, offers a basis for further academic research and practitioner enquiry, which shifts the focus of attention from just technology, to one which emphasises the role of citizens and the increasing opportunities which they now have to participate in local affairs. 


\section{Methodology}

This article is based on research undertaken for the 'SmartGov' (Smart governance of sustainable cities) research project ${ }^{1}$. SmartGov is a four-year (2015-19) collaborative transnational multi-disciplinary research project involving research teams from the Netherlands, the United Kingdom (UK), and Brazil. The project is designed to critically examine governance arrangements, with specific reference to citizen participation and engagement, in Smart city contexts. The project generates new knowledge about Smart cities in that it challenges traditional service delivery oriented eGov perspectives, and because it emphasises the role of citizens and service users in the co-creation process. Core design features of the project are: international comparative research, the importance of contextual and institutional factors; case study research to assess examples of Smart city engagement mechanisms; and, extensive practitioner involvement to identify critical success factors and to provide opportunities for service improvements, especially in the three case study cities examined: Utrecht (Netherlands); Glasgow (UK); Curitiba (Brazil).

Theoretical development within SmartGov is underpinned by a thorough literature review assessing what is already known about Smart city governance. This in turn, is being utilised to inform and guide the empirical case study research through the development of an analytical framework of understanding. The framework is presented in this article in the form of a new model of understanding referred to as the 'technologically-mediated municipal reciprocity model' and which is presented and discussed in more detail in Section 4. The literature review was conducted by the three research teams in 2016 using a literature review

\footnotetext{
${ }^{1}$ SmartGov research project, URL: http://smartgov-project.com
} 
protocol. The review focused on three key areas: [1] technology, including Smart cities, eGov and co-creation; [2] engagement, participatory mechanisms and practices, especially where they utilised new technology (eParticipation); and [3] sustainability, in relation to urban governance practices. It used an iterative approach using online search engines, Google Scholar and through which articles were identified through snowballing techniques [10]. In total, over 150 academic articles were selected for final stage analysis. Of these, approximately $80 \%$ were published between 2010 and 2016, with most authors and cities studied being located in Europe, with the remainder of the authors and cities studied being fairly evenly spread across North and South America, Asia and Australasia. The literature reviewed included academic articles and books, government and practitioner reports, media publications and other 'grey' matter. The articles selected for detailed analysis differed in a number of ways. They adopted different methodological approaches, from case studies; literature reviews including systematic reviews; surveys; ethnographical studies; theory building, and web analysis etc. They also differed in the technologies being explored, ranging from living labs, citizen observatories, eParticipation applications, as well as a number of other digital initiatives. Issues relating to governance were embedded in many of the articles, particularly in the discourse on eParticipation and eDemocracy. Some articles had a specific focus on a particular form of governance, especially civic engagement, and many of the articles promoted the value of technology for urban development and enhanced service provision. Very few articles addressed directly the combination of sustainable urban governance using citizen-centric Smart city technologies, and it was evident from the literature review that there has to date been limited published work on the processes by which citizens are incentivised to engage in co-production and the ingredients necessary for successful sustainable co-production using ICTs in Smart city environments. 


\section{Smart City Governance}

This section of the article engages directly with current discourse around Smart cities, cocreation, co-production, and Smart city governance. It includes an exploration of the contemporary concept of Smart cities, examines the distinction between co-production and co-creation, and considers the role of the citizen in Smart city governance arrangements. It also presents a categorisation of the different ways in which citizens participate in and cocreate Smart city environments.

\subsection{The Smart City}

Providing a precise definition of the term 'Smart city' is not straightforward due to the continually evolving nature of the various components involved, and differences in the conceptual understanding of the term. Whilst the term is relatively new its use is now widespread and is used to capture a range of features of the modern urban environment, including: new models of service delivery [57], innovative use of ICTs [59], new opportunities arising from the Internet of Things [89], and changing dynamics of relationships amongst the actors involved, including the disengaged [75]. The term 'smarter cities' was registered as a trademark by IBM in 2011 and their involvement in the development of Smart cities has been described as "the most developed attempt by a private company to define a model of urban management" [79, p. 307]. Soderstrom et al. [79] refer to the dominant discourse on Smart cities being about efficient and sustainable cities, but that the logic behind the involvement of ICT companies is a commercial logic about market re-positioning so that Smart technologies are seen as a 'must have' asset for cities. Kitchen [43] argues that a profit orientation explains attempts by ICT companies to change the direction of their corporate language on Smart cities 
from a 'top-down' managerially focused one, to a revised 'bottom-up' approach which stresses inclusivity and citizen empowerment. Difficulties in providing a definition or indeed a shared understanding of the concept are often referred to in the academic discourse on Smart cities [61]. Smart city definitions have been described as tending to be "normative and narrow in perspective" [3, p.326], while others contend that there is a void in the literature, with most writers addressing "only technological aspects" of the Smart city [59, p.185]. It has also been claimed that the term smart city is "basically an evocative slogan lacking a well-defined conceptual core and, in this sense, proponents of the smart city are allowed to use the term in ways that support their own agenda" [83, p.884]. In this respect, the dominant discourse on Smart cities is the positive use of new technology to enhance service provision, arguably an agenda driven by service providers and IT companies [85].

The term 'Smart city' can also be synonymous with other related concepts, such as the 'digital city', the 'wired city', or the 'intelligent city', with the developing role of the citizen in this 'mix' becoming increasingly important [77]. These terms reflect the proliferation in the use of digital devices and infrastructure in cities, as well as ever increasing volumes of data, and enables "real-time analysis of city life, new modes of urban governance, and provides the raw material for envisioning and enacting more efficient, sustainable, competitive, productive, open and transparent cities" $[42$, p.1]. With this in mind the core features of a Smart city have been described from a technological perspective as "the application of complex information systems to integrate the operation of urban infrastructure and services such as buildings, transportation, electrical and water distribution, and public safety" [32, p.2]. The apparent 'self-congratulatory' nature of the Smart city can also be challenged, with it being suggested that Smart urbanism should put societal problems first and not look to Smart 
technology for the answers. A case can be made for greater engagement of the citizen and communities in designing solutions to their problems [35].

Discussions about what constitutes a 'Smart city' are increasingly, linked to the concept of sustainability and the 'sustainable Smart city', where the transformative power of technology is realised if it offers sustainable long-term solutions, and engages citizens in participatory activities linked directly to the services which they need. In a sustainability context, the sustainable Smart city provides "the potential for citizens to improve their lives in the urban context and sustaining it for the future" $[18, p .5]$. Components of the sustainable Smart city might include government-citizen engagement and participation, leading to cocreation and co-production relative to: the planned use and location of green spaces, waste disposal and recycling, air quality targets, traffic congestion, water management and use of natural resources. With regards to energy usage, the innovative use of ICTs provides opportunities for intelligent uses of energy in a range of contexts, such as in buildings, transport, street lighting, water usage, and energy-capture/energy-transfer initiatives, leading to reduced carbon emissions. Sustainability in this context is much more than simply being environmentally friendly, it is about designing organisational structures and processes, and institutional norms and values that will exist over time, in a manner that enriches citizens' lives and at the same time prioritises the efficient use of societal resources. Smart city governance occurs in situations where actors, including citizens, policy-makers, practitioners, private and third sector organisations, technologies, and the physical and virtual features of the Smart city, engage and interact through the facilitating medium of innovative ICTs, to help to meet the challenges of urban problems. Outcomes, or 'promises', from these interactions might include co-production, leading to shared learning, and improved decision-making. This is not to argue that Smart cities will automatically improve citizens' lives, only through further 
robust empirical research can this claim be validated. Instead, a more nuanced understanding of the Smart city is required, one which emphasises socio-technical structures and relations in Smart governance arenas [52].

\subsection{Co-production and Co-creation}

There may be a disconnect in the discourse between the perceived transformative potential of ICTs and their realisation in complex public service environments, where administrative solutions associated with service delivery may be easier to deliver than radical ICT-oriented engagement and co-production activities. There is also probably a discord between perceived benefits evident in the literature and the actual practices delivered 'on the ground'. To date, co-production approaches have mostly been 'government-centric' as opposed to 'citizencentric' [50], and it is important to understand the context of citizen engagement and participation in the delivery of services, for example in planning mechanisms where the concern of the policy-makers in local or central government may be more about the distribution of resources, rather than the engagement of citizens, who in practice are kept at 'arms-length'. To aid our understanding of the different roles of the citizen and government, it is important to distinguish between co-production and co-creation. The term 'coproduction' is claimed to have originated from the work of Parks et al. $[70,68]$, where it was found that the trust of smaller communities who knew their local police officers was a critical success factor in realising enhanced policing. In such an environment, the production of public services did not happen in the traditional top-down bureaucratic way, but was the result of the active engagement of citizens or service users in the production process. Co-production has been defined to include the agencies charged with delivering the particular service, and the individuals (service users) or communities which receive it $[36,67]$. 
Alford and Yates [2] assert that the extent to which citizens are inclined to co-produce is related to their satisfaction with services received. Bovaird [14] argues that involving service users in service planning is at odds with New Public Management which points to service providers being responsive to the needs of their communities without necessarily engaging them in co-production [22]. The literature on co-production, although presenting a thorough analysis of new practices in the public sector, fails to address the emerging importance of the role of social media, and the 'huge potential' that the Internet now provides [50].

The terms co-production and co-creation are often used interchangeably, and are used to reflect the role of citizens and service users in the creation or production of services and value [68]. This is especially so in relation to the use of new ICTs for service provision. Conditions of co-creation exist when there is "active involvement of end-users in various stages of the production process" and whilst there are some similarities in the definitions "the co-creation literature puts more emphasis on co-creation as value" in itself [87, p.1335]. One way to differentiate the terms would be to think about the core terms themselves. Coproduction implies involvement in the production and consumption of a service and therefore lends itself to perspectives focused on service design and service users, whereas co-creation implies involvement in processes creating public services more generally, including the cocreation of value, therefore lending itself to citizen engagement in public policy processes, where the outcome of the engagement may focused more broadly on society or a community than on an individual citizen. What is of interest in this article is how citizens co-produce governance in a Smart city environment, the mechanisms by which this is achieved and the degree to which these processes are shaped and controlled by municipalities.

\subsection{Participating in the Smart City}


Citizens participate in the Smart city in a variety of ways, some very traditional, but others are innovative mechanisms facilitated by new ICTs. Some of the participation is oriented towards the consumption of services, whilst other forms are oriented towards influencing decision and policy making. There is extensive literature on eParticipation [90], and eConsultation [86], but much of this literature concentrates on using ICTs to support traditional participatory and consultative mechanisms. The critical feature of the Smart city environment is utilisation of information flows in innovative 'Smart' ways. The data embedded in these information flows emanates from administrative data, service data, data generated by new sensory devices and data generated via social media and open data. In a Smart city, new sources of data originate from new technological applications, or from the combination of existing datasets. Despite the growing proliferation of publicly available datasets [82], there appears to be a conflict in the desire for the use of open data and the experiences of citizens and other groups in actually using them [88]. One reason for the lack of engagement with open data might be attributable to a data literacy deficit, both in terms of the skills of the providers of the datasets in making them publicly accessible, and of citizens, in being able to interpret and use them for their own purposes [84].

Participating in the Smart city is a physical and a virtual experience, and services received will derive from digital personas. However, participating in a Smart city may also be involuntary, for example, sensory devices counting footfall, intelligent street lighting, and traffic congestion, etc. Whilst participating in the Smart city environment is increasingly digital and virtual, many of the contemporary mechanisms involve human and institutional interventions and are not initiated by technology, but by local communities. Table 1, provides various examples of Smart city participation and co-production, which could be placed alongside Arnstein's [4] ladder to determine the extent of participation and engagement. This 
could then be used to demonstrate which mechanisms allow for true participation, which only occurs when citizens exert control over the process. It could actually be the case, that they can go anywhere on Arnstein's [4] ladder depending on how they are designed and used.

\section{INSERT HERE: Table 1. Mechanisms of Smart City Participation and Co-production}

The Smart city is credited with introducing a number of innovative participatory spaces, where the physical and the digital are blended together, and through which citizens are able to actively enagage with processes that shape public services and policy. Published literature offers up lots of descriptive examples of these 'spaces' [76]. They include; hackathons, living labs, fablabs and maker spaces, Smart urban labs, citizen dashboards, Smart citizens labs, gamification, open datasets and crowdsourcing. Additionally, there are several specialised programs which are used (mainly by practitioners) for adding value to planning support systems, such as the Geographic Information System-based CommunityViz [71] and the modelling-based program UrbanSim [23]. These Smart city oriented participatory governance practices are becoming commonplace in Smart cities across the globe. Table 1 below briefly describes each participative practice. They share a number of core features. Firstly, they all have a focus on technology, whether it is reusing existing data or designing new applications. Secondly, they all require the input and engagement of citizens, whether it is a select group of citizens or the citizenry in general. Thirdly, they involve a physical as well as a virtual digital interaction. And, fourthly, each requires an initial stimulus from formal public agencies in order to create the space and provide opportunities for engagement. Whilst all these practices appear novel and exciting, and offer opportunities for better public services and policy, their practice differs from city to city, as institutional contexts change. A full evaluation of each is 
required in order to assess the extent of citizen engagement and the outcome of their participation. There is also a continuing challenge for policy makers in how to sustain these examples of Smart city participation over time, to ensure that not only do they become systemic, but so too does the engagement and participation of all of the actors involved. So, questions relevant to any participatory practice, such as: 'does citizen engagement lead to changes in services and policy?', 'which citizens are engaged and why?', and 'to what extent do citizens shape and control the process?', are just as pertinent here as they would be for traditional participatory practice, and there should not be the assumption that because new technologies are involved engagement will be 'better' [9].

\subsection{Incentivisation and Gamification}

One relatively recent engagement practice is to incentivise citizen participation through some form of applied gamification. The gamification of public services is a novel feature of the Smart city environment [5] and may appeal to the playful, problem-solving and competitive side of human nature, where it can be used to motivate positive behaviours and discourage unproductive ones [28]. It is likely that the use of this transformational engagement-medium will expand as citizens are increasingly exposed to such practices in their everyday lives, through the widespread use of mobile telephone apps and games, and activity monitors such as fitness trackers. Mallon [48] draws parallels with the application of gamification techniques across a number of sectors, including higher education, and claims that the use of digital games is almost 'ubiquitous' in social media. Smart meters and energy apps have been introduced to monitor home energy use $[25,27]$, they offer the potential to moderate citizens' behaviour, the results of which could be reduced fuel costs, and an environmental benefit in terms of a 'feel-good factor' through acting sustainably [60]. Participation in gaming 
can have positive effects on people's lives [49], including the development of problem solving skills, and the use of well-designed gamification platforms, can also lead to the creation of successful and enduring citizen-state relationships [38]. Whilst gamification may be an appealing medium for service providers, the extent to which it represents a radical form of eGov is still to be determined, and there may be a temptation to conflate engagement with participation [29].

\section{Technologically-mediated Municipal Reciprocity}

The Smart city environment, through the evolution of new citizen-state informational relations and mediated by new ICTs, is facilitating new forms of governance. This new era allows citizens and service users to have increasing opportunities for a more direct role in the design and delivery of public services and policy, and hence the emerging use of the terms like co-design, co-creation and co-production. The extent to which this evolution empowers the citizenry remains to be seen and is dependent upon a number of factors, including critically, the degree to which citizens are willing and able to engage, and the degree to which existing institutional norms, especially those associated with established political and policy processes, are resistant to change and amenable to the potential for shifts in established power structures.

For disengaged citizens, who may have little affinity with their local municipality, and little or no inclination to participate in local affairs, their question to the invitation offered by service providers to participate, might well be: 'what's in it for me?' The need to incentivise citizens becomes critical, as does transparency in the transformative change in the distribution of power from a centralised top-down government-centric approach, to a more decentralised and citizen-centric approach, a process which crucially involves some form of 
benefit or reward for both for the citizen and the municipality. Reciprocity is central to the co-production process and "one way of comprehending this jointness is to see co-production as a reciprocal process: it entails the government organisation and the citizen each giving something, such as time and effort, to the other" [2, p.846].

The idea of some form of mutual reciprocity is linked to the notion of social capital [73], whereby societal groupings and communities develop the skills and knowledge for selfdeterminism and empowerment, and that this occurs alongside political and community leadership in a mutually beneficial relationship [34]. This occurs in the absence of traditional bureaucratic governance structures following New Public Management [66, 12]. Reciprocity becomes a key ingredient in the governance mix and is a core characteristic in contemporary citizen-state relations, which are increasingly mediated by new ICTs embedded in new participatory practices [51].

Whilst it is clear that the Internet and social media offer new potentialities for engagement, communication and interaction with citizens, and thereby reaching hitherto untouched audiences, it is at the same time unclear how these process will 'play out in practice', whether or not their potential will be realised, and how citizens will experience and respond to reciprocity opportunities. The various forms of incentives to participate may not be strong enough 'hooks' to catch and retain the involvement of Internet 'lurkers' and other disengaged citizens, without the prospect of some form of 'reward' for their participation, which in turn implies some form of control over the creative process. The desirability for reciprocity points to a new dynamic which we conceptualise as 'technologically-mediated municipal reciprocity', where municipalities and citizens engage, interact and co-produce using ICTs and social media, and where there are incentives and rewards identified for both parties, in the creation of shared Smart city governance. The 'technologically-mediated 
municipal reciprocity' approach is intended to recognise the underlying significance of new ICTs, without eulogising its potential, and at the same time emphasising that there are many components necessary to realise an arrangement which is truly reciprocal and mutually beneficial. In this respect, the technologically-mediated municipal reciprocity approach is an heuristic device, a discursive model highlighting the components required to facilitate reciprocal relationships, and thereby helping us to better understand the ingredients necessary for Smart city governance. As such, it highlights the critical role played by technology in supporting and mediating citizen-state relations, and especially inputs into the process and shared outcomes. Where synergy exists and where citizens and governance agencies become mutually dependent on processes shaped by the informational and communication activities embedded in new ICTs, then the processes and structures of governing, including the design and delivery of public policy and services, are mediated, but not determined, by technology, and co-created by citizens and the state. In doing so, governance becomes dependent upon co-produced informational activities and relationships.

Figure 1. Illustrates the technologically-mediated municipal reciprocity model and highlights the inputs and outcomes, or 'promises', implied by the approach. New ICTS play a critical role in the model as they are the conduit mediating inputs and shaping relations. They are part of the broader institutional and cultural context shaping activity and without which governance could not take place. This model allows us to comprehend some of the subtle and nuanced contexts of Smart city governance. It highlights the emergent roles played by municipalities and citizens in a contextual governance process which is both simultaneously bottom-up and top-down. The elements depicted in Figure 1 derive from the themes evident in the literature review, the specified inputs are illustrative and are not intended to be 
definitive or comprehensive. The intention here is not to explain in granular detail how reciprocity happens, but to identify reciprocity as a core component of contemporary governance and the municipal and citizen inputs necessary for reciprocity to be mutually beneficial. In practice, the process is unlikely to be 'neutral' and is likely to be shaped by an array of vested interests, as these interests seek to maximise their own personal utility from the process. Municipal inputs in the technologically-mediated municipal reciprocity process are designed to facilitate citizen engagement, whilst citizen inputs imply a degree of trust in the municipality and a willingness to input into the governance process, and in this respect these inputs are related and not independent variables. The results of this interaction are shown in the form of more meaningful and sustainable benefits to local communities and offer a stark contrast to traditional governance practices.

The model can also be used to map a particular context and 'who' is involved in cocreation and governance, 'how' are they co-creating, 'what' is the role of new ICTs, and to what degree are the outcomes linked to the various inputs? In this respect, the model accommodates rich contextual features of the environment and does not presuppose deterministic ICT solutions. The model also allows us to question the extent to which outcomes are mutually beneficial and whether or not processes that appear reciprocal are shaped and determined by vested interests. It should be noted, that the outcomes suggested by the model can be either positive or negative, and that the model offers the promise of potential reciprocity. The idealised situation proposed by the model is not meant to reflect 'real life', rather it is a proposition to be tested empirically. In this respect, the model is merely a device that allows us to 'unpick' Smart city governance and to understand better how governance and technologies are co-evolving together. In this respect, the technologicallymediated municipal reciprocity model should be viewed as a way of understanding the 
complex Smart city governance environment, its key components, and how they interact and relate to one another. It highlights the importance of reciprocity and shared benefits, and the underlying role played by ICTs. The approach can be used as a generic narrative about the components of reciprocal relationships.

\section{INSERT HERE: Figure 1: Technologically-mediated Municipal Reciprocity}

Can a model of technologically-mediated municipal reciprocity offer insight or be applied by practitioners, analysts or policy-makers? Analysing the 'success' of a Smart city is almost as conceptually difficult as providing a definition of a Smart city, and as a consequence can be carried out via different levels of enquiry. For example, the business community might use 'hard' indicators concerning inward investment, entrepreneurial start-ups, or technological infrastructure. Educationalists might regard digital and data literacy as a good indicator. Environmentalists could use a whole variety of indicators concerning recycling, air and noise pollution. But which 'soft' indicators would the citizen use to categorise the factors which contribute to the making of a successful Smart city? Have interventions made a difference to their lives, socially, economically, culturally or recreationally? Is there a greater sense of place, or is their community more resilient? Is the city and environs easier to navigate? Is it a healthier place to live, work and play? Have they participated in any shared learning or citywide decision-making? The model of technologically-mediated municipal reciprocity, which has at its core new ICTs blended alongside contextual factors, sets out the key inputs required by both municipalities and citizens (or citizens' groups), if they are to work together to achieve reciprocal benefits and promises for both parties. 


\section{Concluding Discussion}

Smart cities are at the nexus of a range of data flows, emanating from new sensory devices, existing datasets and big data processes. They provide exciting opportunities for citizen engagement in service re-design and co-production, and in influencing public policy agendas and processes. In this article, we have presented a range of new innovative citizen engagement practices facilitated by new ICTs, from living labs through to hackathons and the use of open datasets. Many of these practices mirror the experimental nature of Smart cities, in that they are small-scale minority activities involving small groups of citizens and service users. In this respect, the Smart city agenda has provided an environment malleable to experimentation and the trialing of new initiatives. This is one reason why no two Smart cities are the same, they are different in their institutional and organisational contexts and practices, and also in the applications being tested. The entrepreneurial experimental culture encouraged by Smart cities lends itself to 'proof of concept' initiatives, often trialed in small pilots with no assumption that there will be widespread implementation. Whilst this may be a good way of seeing 'what works' it also means that these initiatives are unrepresentative of the citizenry in general and arguably not suitable for universal application. This is especially important for citizen engagement mechanisms which are often assumed to provide universal participatory opportunities.

The emergence of sustainable engagement and governance practices are dependent on several variables, including: data literacy of service users and providers, access to the Internet, use of social media as a vehicle for engagement, open access arrangements to datasets, protocols for collecting and processing administrative/personal data, levels of eGov expertise, and, existing practices and norms around citizen participation. These represent sizeable challenges for realising widespread citizen engagement through Smart city 
technologies [65]. There are significant issues to be addressed around how representative such engagement mechanisms are, although this is a concern for all participatory practices, and also the extent to which such mechanisms lead to 'real' change. The latter is important because citizens will only continue to participate if they derive some value from doing so. A further issue relates to the involuntary use of citizen-generated data, often from social media and used for public policy and service purposes, without the users' consent or knowledge. This raises ethical and privacy issues that relate to a raft of Smart city practices. Many of these issues are empirical questions which require robust evaluation and testing 'in the field' before concrete judgments can be made.

By emphasising roles played by 'Smart' technologies in fostering the co-production of governance this article enhances our understanding of the requirements for sustainable urban development when drivers for sustainable and resilient societies are increasingly technologically-oriented. Whilst much of the literature points to the transformative potential of ICTs it is unclear which technologies work best in which contexts or the factors critical in realising their potential. The 'technologically-mediated municipal reciprocity' vision of Smart city governance proposes a model of shared benefits mediated by new ICTs. It points to Smart city governance as consisting of a number of complex interwoven interactions and relationships, highlighting the 'ingredients' necessary for mutually beneficial reciprocity, and can be used as a discursive model to understand the Smart city environment. Smart City governance, as discussed in this article, is increasingly reliant on informational relationships between citizens and the state and mediated by new technologies in a symbiotically dependent arrangement. By emphasising different ingredients this model elevates the importance of context, of process, and of the evolution of co-joined technical, human and institutional practices, as the best way of comprehending Smart city governance. 


\section{Endnote}

The research presented derives from 'SmartGov': 'Smart Governance of Sustainable Cities', a four year collaborative transnational multi-disciplinary research project on the value of ICTs for engaging citizens in governance of sustainable cities (2015-2019). Funding Councils in the United Kingdom (ESRC); Netherlands (NWO), and Brazil (FAPESP) have co-funded the research. The three project partners are Utrecht University, (Netherlands); University of Stirling (United Kingdom), and Fundação Getulio Vargas, Sao Paulo, (Brazil). The ESRC Grant reference number is: ES/N011473/1. SmartGov research project website, URL: http://smartgov-project.com.

\section{References}

[1] Abdoullaev, A. (2011). Keynote: A smart world: A development model for intelligent cities. In the 11th IEEE international conference on computer and information technology (CIT), Pafos, Cyprus.

[2] Alford, J., \& Yates, S. (2015). Co-production of public services in Australia: The roles of government organisations and co-producers. Australian Journal of Public Administration, 75(2), 159-175.

[3] Anttiroiko, A.V., Valkama, P., \& Bailey, S.J. (2014). Smart cities in the new service economy: building platforms for smart services. Al \& society, 29(3), 323-334.

[4] Arnstein, S. (1969). A ladder of participation. Journal of the American Institute of Planners, $35(4), 216-244$.

[5] Asquer, A. (2014). Not just videogames: Gamification and its potential application to public services. In E. F. Halpin, D. Griffin, C. Rankin, L. Dissanayake \& N. Mahtab (Eds.), Digital public 
administration and e-government in developing nations: policy and practice, (pp. 146-165). IGI Global.

[6] BBC News. (2014). New app launched to boost cycling routes in Glasgow. http://www.bbc.co.uk/news/uk-scotland-glasgow-west-30036227/.

[7] Baccarne, B., Schuurman, D., Mechant, P., \& De Marez, L. (2014). The role of urban living labs in a smart city. In ISPIM conference proceedings, Dublin, Ireland (1). The International Society for Professional Innovation Management (ISPIM).

[8] Bakıcı, T., Almirall, E., \& Wareham, J. (2013). A smart city initiative: the case of Barcelona. Journal of the Knowledge Economy, 4(2), 135-148.

[9] Baldwin, J. N., Gauld, R., \& Goldfinch, S. (2012). What public servants really think of egovernment. Public Management Review, 14(1), 105-127.

[10] Baltar, F., \& Brunet, I. (2012). Social research 2.0: virtual snowball sampling method using Facebook. Internet Research, 22(1), 57-74.

[11] Batty, M., Axhausen, K. W., Giannotti, F. Pozdnoukhov, A., Bazzani, A., Wachowicz, M., Ouzounis, G. \& Portugali, Y. (2012). Smart cities of the future. The European Physical Journal Special Topics, 214(1), 481-518.

[12] Bevir, M. (2011). Governance and governmentality after neoliberalism. Policy \& Politics, 39(4), 457-471.

[13] Bonsón, E., Torres, L., Royo, S., \& Flores, F. (2012). Local e-government 2.0: Social media and corporate transparency in municipalities. Government Information Quarterly, 29(2), 123 $-132$.

[14] Bovaird, T. (2007). Beyond engagement and participation: User and community coproduction of public services. Public Administration Review, 67(5), 846-860. 
[15] Bovaird, T., \& Loeffler, E. (2010). User and community co-production of public services and public policies through collective decision-making: the role of emerging technologies. In T. Brandsen, \& M. Holtzer, (Eds.), The future of governance, selected papers from the fifth transatlantic dialogue on public administration (pp. 231-260). Washington DC: national centre for public performance (NCPP).

[16] Brabham, D.C. (2009). Crowdsourcing the public participation process for planning projects. Planning Theory, 8(3), 242-262.

[17] Castelnovo, W., Misuraca, G., \& Savoldelli, A. (2015). Citizen's engagement and value coproduction in smart and sustainable cities. In International conference on public policy, 1-16. Milan.

[18] Cavada, M., Hunt, D.V., \& Rogers, C.D. (2014). Smart cities: Contradicting definitions and unclear measures. In World Sustainability Forum, 1-12.

[19] Chourabi, H., Nam, T., Walker, S., Gil-Garcia, J.R., Mellouli, S., Nahon, K., Pardo, T.A., \& Scholl, H.J. (2012). Understanding smart cities: An integrative framework. In System Science (HICSS), 2012 45th Hawaii International Conference on System Sciences, 2289-2297.

[20] Clarke, A., \& Margetts, H. (2014). Governments and citizens getting to know each other? Open, closed, and big data in public management reform. Policy \& Internet, 6(4), 393-417. [21] Devisch, O., Poplin, A., \& Sofronie, S. (2016). The Gamification of civic participation: Two experiments in improving the skills of citizens to reflect collectively on spatial issues. Journal of Urban Technology, 23(2), 81-102.

[22] Dunleavy, P., Margetts, H., Bastow, S., \& Tinkler, J. (2006). New public management is dead-long live digital-era governance. Journal of public administration research and theory, 16(3), 467-494. 
[23] Geertman, S., Ferreira Jr, J., Goodspeed, R., \& Stillwell, J. (2015). Introduction to planning support systems and smart cities. In Planning support systems and smart cities, 1-17. Switzerland: Springer International Publishing.

[24] Gil-Garcia, J.R., Helbig, N., \& Ojo, A. (2014). Being smart: Emerging technologies and innovation in the public sector. Government Information Quarterly, 31, 11-18.

[25] Glasgow City Council. (2013). TSB future cities demonstrator - Glasgow city management system. Report by Alastair Brown, to Sustainability and the Environment Policy Development Committee, 20.03.13.

http://www.glasgow.gov.uk/councillorsandcommittees/viewSelectedDocument.asp?c=P62 AFQ81Z3NTDNZL/.

[26] Glasgow City Council. (2014). Future city Glasgow hackathons, Report by Alastair Brown, to Sustainability and the Environment Policy Development Committee, 26.11.14. https://www.glasgow.gov.uk/councillorsandcommittees/viewDoc.asp?c=P62AFQUTDXNTOG $2 \mathrm{U} /$.

[27] Glasgow City Council. (2015). Future city Glasgow, energy efficiency demonstrator, End Stage Report. July.

http://futurecity.glasgow.gov.uk/reports/FC_Reports_2015_Energy_V2.pdf).

[28] Glover, I. (2013). Play as you learn: gamification as a technique for motivating learners. In J. Herrington, A. Couros, \& V. Irvine, (Eds.), Proceedings of world conference on educational multimedia, hypermedia and telecommunications, 1999-2008. Chesapeake, VA, AACE.

[29] Gordon, E., \& Baldwin-Philippi, J. (2014). Playful civic learning: Enabling lateral trust and reflection in game-based public participation. International Journal of Communication, 8, 28. [30] Granier, B., \& Kudo, H. (2016). How are citizens involved in smart cities? Analysing citizen participation in Japanese Smart Communities. Information Polity, 21(1), 61-76. 
[31] Gray, R. (2010). Is accounting for sustainability actually accounting for sustainability... and how would we know? An exploration of narratives of organisations and the planet. Accounting, Organizations and Society, 35(1), 47-62.

[32] Harrison, C., \& Donnelly, I.A. (2011). A theory of smart cities, in Proceedings of the 55th Annual Meeting of the International Society for the System Sciences, Hull, UK, 55(1), 1-15.

[33] Hastings, A., Bailey, N., Bramley, G., Croudace, R., \& Watkins, D. (2014). Managing the middle classes: Urban managers, public services and the response to middle-class capture. Local Government Studies, 40(2), 203-223.

[34] Haus, M., \& Klausen, J. E. (2011). Urban leadership and community involvement: Ingredients for good governance? Urban Affairs Review, 47(2), 256-279.

[35] Hollands, R. G. (2014). Critical interventions into the corporate smart city. Cambridge Journals of Regions Economics and Society, 8(1), 61-77.

[36] Hupe, P. (1993). The politics of implementation: Individual, organisational and political co-production in social services delivery. New agendas in the study of the policy process. Hemel Hempstead: Harvester Wheatsheaf, 130-151.

[37] Johnson, P., \& Robinson, P. (2014). Civic hackathons: Innovation, procurement, or civic engagement? Review of Policy Research, 31(4), 349-357.

[38] Kelley, T.M., \& Johnston, E. (2012). Discovering the appropriate role of serious games in the design of open governance platforms. Public Administration Quarterly, 36(4), 504-554.

[39] Kim, S., \& Lee, J. (2012). E-participation, transparency, and trust in local government. Public Administration Review, 72(6), 819-828.

[40] King, S., \& Cotterill, S. (2007). Transformational government? The role of information technology in delivering citizen-centric local public services. Local Government Studies, 33(3), 333-354. 
[41] Kisby, B. (2010). The Big Society: power to the people? The Political Quarterly, 81(4), 484491.

[42] Kitchin, R. (2014). The real-time city? Big data and smart urbanism. GeoJournal, 79(1), 114.

[43] Kitchin, R. (2015). Making sense of smart cities: addressing present shortcomings, Cambridge Journal of Regions, Economy and Society, 8(1), 131-136.

[44] Lee, D.F., Felix, J.R.A., He, S., Offenhuber, D., \& Ratti, C. (2015). CityEye: Real-time visual dashboard for managing urban services and citizen feedback loops. In Computers in Urban Planning and Urban Management Conference, Cambridge, MA, 2015.

[45] Linders, D. (2012). From e-government to we-government: Defining a typology for citizen coproduction in the age of social media. Government Information Quarterly, 29(4), 446-454. [46] Lips, M. (2012). E-government is dead: Long live public administration 2.0. Information Polity, 17(3, 4), 239-250.

[47] Lofstedt, U. (2012). E-government-assessment of current research and some proposals for future directions. International Journal of Public Information Systems, 1(1), 39-52.

[48] Mallon, M. (2013). Gaming and gamification. Public Services Quarterly, 9(3), 210-221.

[49] McGonigal, J. (2011). Reality is broken: Why games make us better and how they can change the world. USA: Penguin.

[50] Meijer, A. J. (2011). Networked coproduction of public services in virtual communities: From a government-Centric to a community approach to public service support. Public Administration Review, 71(4), 598-607.

[51] Meijer, A. (2012). Co-production in an information age: Individual and community engagement supported by new media. VOLUNTAS: International Journal of Voluntary and Nonprofit Organizations, 23(4), 1156-1172. 
[52] Meijer, A., \& Bolívar, M. P. R. (2016). Governing the smart city: a review of the literature on smart urban governance. International Review of Administrative Sciences, 82(2), 392-408. [53] Meijer, A. J., Gil-Garcia, J. R., \& Bolívar, M. P. R. (2016). Smart city research contextual conditions, governance models, and public value assessment. Social Science Computer Review, 34(6), 647-656.

[54] Mossberger, K., Wu, Y., \& Crawford, J. (2013). Connecting citizens and local governments? Social media and interactivity in major US cities. Government Information Quarterly, 30(4), 351-358.

[55] Muhlberger, P., Stromer-Galley, J., \& Webb, N. (2011). Public policy and obstacles to the virtual agora: Insights from the deliberative e-rulemaking project. Information Polity, 16(3), 197-214.

[56] Mulder, I. (2015). Opening up: Towards a sociable smart city. In M. Foth et al. (Eds.), Citizen's Right to the Digital City (pp. 161-173). Singapore: Springer.

[57] Mulligan, C. E., \& Olsson, M. (2013). Architectural implications of smart city business models: an evolutionary perspective. IEEE Communications Magazine, 51(6), 80-85.

[58] Nam, T., \& Pardo, T. A. (2011a). Conceptualizing smart city with dimensions of technology, people, and institutions. In Proceedings of the 12th annual international digital government research conference: digital government innovation in challenging times, 282291.

[59] Nam, T., \& Pardo, T.A. (2011b). Smart city as urban innovation: Focusing on management, policy, and context. In Proceedings of the 5th International Conference on Theory and Practice of Electronic Governance, Association of Computing Machinery, 185-194.

[60] Naus, J., Spaargaren, G., van Vilet, B.S.M., \& van der Horst, H.M. (2014). Smart grids, information flows and emerging domestic energy practices. Energy Policy, 68, 436-446. 
[61] Neirotti, P., De Marco, A., Cagliano, A.C., Mangano, G., \& Scorrano, F. (2014). Current trends in smart city initiatives: Some stylised facts. Cities, 38, 25-36.

[62] Nilsson, E. M. (2012). The making of a maker-space for open innovation, knowledge sharing and peer-to-peer learning. In S. Sonvilla-Weiss, \& K. Owen (Eds.). Future learning spaces: Designs on elearning conference proceedings, 293-298.

[63] Nolan, R. L. (1979). Managing the crises in data-processing. Harvard Business Review, Boston, 57(2), 115-126.

[64] Nyström, A.G., Leminen, S., Westerlund, M., \& Kortelainen, M. (2014). Actor roles and role patterns influencing innovation in living labs. Industrial Marketing Management, 43(3), 483-495.

[65] Oliveira, Á., \& Campolargo, M. (2015). From smart cities to human smart cities. In $48^{\text {th }}$ Hawaii International Conference on System Sciences, IEEE, 2336-2344.

[66] Osborne, S.P. (2010). The new public governance: Emerging perspectives on the theory and practice of public governance. Abingdon, UK: Routledge.

[67] Osborne, S.P., \& Strokosch, K. (2013). It takes two to tango? understanding the coproduction of public services by integrating the services management and public administration perspectives. British Journal of Management, 24(S1), S31-S47. Wiley Online Library.

[68] Osborne, S.P., Radnor, Z., \& Strokosch, K. (2016). Co-production and the co-creation of value in public services: A suitable case for treatment? Public Management Review, 18(5), 639-653.

[69] Ostrom, E. (2013). Foreword. In V. Pestoff, T. Brandsen, \& B. Verschuere, (Eds.), New public governance, the third sector, and co-production. New York: Routledge. 
[70] Parks, R. B., Baker, P. C., Kiser, L., Oakerson, R., Ostrom, E., Ostrom, V., \& Wilson, R. (1981). Consumers as coproducers of public services: Some economic and institutional considerations. Policy Studies Journal, 9(7), 1001-1011.

[71] Pelzer, P., Geertman, S., \& van der Heijden, R. (2016). A comparison of the perceived added value of PSS applications in group settings. Computers, Environment and Urban Systems, 56, 25-35.

[72] Pestoff, V. (2014). Collective action and the sustainability of co-production. Public Management Review, 16(3), 383-401.

[73] Putnam, R. D. (1995). Bowling alone: America's declining social capital. Journal of Democracy, The Johns Hopkins University Press, 6(1), 65-78.

[74] Sæb $\varnothing, \varnothing .$, Rose, J., \& Flak, L. S. (2008). The shape of eparticipation: Characterizing an emerging research area. Government Information Quarterly, 25(3), 400-428.

[75] Saunders, T. \& Baeck, P. (2015). Rethinking smart cities from the ground up. Nesta, public reports.

[76] Schaffers, H., Komninos, N., Pallot, M., Trousse, B., Nilsson, M., \& Oliveira, A. (2011). Smart cities and the future internet: Towards cooperation frameworks for open innovation. In The Future Internet Assembly, 431-446. Berlin Heidelberg: Springer.

[77] Schuurman, D., Baccarne, B., De Marez, L., \& Mechant, P. (2012). Smart ideas for smart cities: investigating crowdsourcing for generating and selecting ideas for ICT innovation in a city context. Journal of theoretical and applied electronic commerce research, 7(3), 49-62.

[78] Smith, A. G., Hielscher, S., Dickel, S., Soderberg, J., \& van Oost, E. (2013). Grassroots digital fabrication and makerspaces: Reconfiguring, relocating and recalibrating innovation? University of Sussex, SPRU Working Paper, SWPS, 2013-02. 
[79] Soderstrom, O., Paasche, T., \& Klauser, F. (2014) Smart cities as corporate story telling, City, 18(3), 307-320.

[80] Szkuta, K., Pizzicannella, R., \& Osimo, D. (2014). Collaborative approaches to public sector innovation: A scoping study. Telecommunications Policy, 38(5-6), 558-567.

[81] Taylor, J.A., \& Webster, C.W.R. (1996). Universalism: Public services and citizenship in the information age. Information Infrastructure and Policy, 5(3), 217-233.

[82] United Kingdom Government. (2015). Statutory Instruments, 2015, No.1415. Public sector information; The re-use of public sector information regulations 2015.

[83] Vanolo, A. (2014). Smartmentality: The smart city as disciplinary strategy. Urban Studies, 51(5), 883-898.

[84] Veeckman, C., \& van der Graaf, S. (2015). The city as living laboratory: Empowering citizens with the citadel toolkit. Technology Innovation Management Review, 5(3), 6-17.

[85] Viitanen, J., \& Kingston, R. (2014). Smart cities and green growth: outsourcing democratic and environmental resilience to the global technology sector. Environment and Planning A: Economy and Space, 46(4), 803-819.

[86] Virkar S. (2014). Consulting the British public in the digital age: Emerging synergies and tensions in the government 2.0 landscape. In L. Anthopoulos \& C. Reddick, (Eds.), Government e-Strategic Planning and Management. Public Administration and Information Technology, 3. Springer, New York, NY.

[87] Voorberg, W.H., Bekkers, V.J., \& Tummers, L.G. (2015). A systematic review of co-creation and co-production: Embarking on the social innovation journey. Public Management Review, 17(9), 1333-1357.

[88] Worthy, B. (2015). The impact of open data in the UK: Complex, unpredictable, and political. Public Administration, 93(3), 788-805. 
[89] Xia, F., Yang, L.T., Wang, L., \& Vinel, A. (2012). Internet of things. International Journal of Communication Systems, 25(9), 1101.

[90] Zheng, Y. (2017). Explaining citizens' e-participation usage, Functionality of eparticipation applications. Administration and Society, 49(3), 442-423.

[91] Zo!City. (2016). Amsterdam pilot transformcity.

https://amsterdamsmartcity.com/projects/transform-city-zocity-pilot. 
Table 1. Mechanisms of Smart City Participation and Co-production

\begin{tabular}{|c|c|}
\hline Type & Description \\
\hline Hackathons & $\begin{array}{l}\text { Civic engagement events normally organised by a public authority, lasting one to two days, } \\
\text { and having a competitive element with prizes available [26]. Groups of programmers, } \\
\text { designers, computer club members, and Small and Medium-sized Enterprises (SMEs) come } \\
\text { together in teams to use open data with the intention of creating software solutions or } \\
\text { programmes to help address ongoing city issues. The staging of Hackathons signals a } \\
\text { municipality's commitment to open, transparent and participative government [37]. }\end{array}$ \\
\hline Living Labs & $\begin{array}{l}\text { Living labs are used for developing new products, testing prototypes or ideas involving ICTs, } \\
\text { where citizens co-produce with other citizens and industry professionals by contributing } \\
\text { their opinions, knowledge and expertise. The living lab can either be a physical or a virtual } \\
\text { reality, and with the users shaping "the innovation in their daily real-life environments." } \\
\text { [64, p.483]. The strength of the living lab is in the innovation generated through the strength } \\
\text { of relationships amongst the participants [56]. }\end{array}$ \\
\hline $\begin{array}{l}\text { Fablabs and } \\
\text { maker spaces }\end{array}$ & $\begin{array}{l}\text { Fablabs (fabrication laboratories) are a form of living lab, with the emphasis on community- } \\
\text { based shared learning, and production of either solutions to societal issues using ICTs (and } \\
\text { often social media), or the physical production of a commercial item often involving the } \\
\text { recycling of materials [78]. Maker spaces are a form of fablab, where experimentation with } \\
\text { technologies can take place within the confines of the laboratory, but with the potential for } \\
\text { shared learning which extends outwards to the city [62]. }\end{array}$ \\
\hline $\begin{array}{l}\text { Smart Urban } \\
\text { Labs }\end{array}$ & $\begin{array}{l}\text { Smart urban labs are also a form of living lab, often at the spatial scale of the city, again } \\
\text { with a strong emphasis on innovation, involving the testing of ideas and products by } \\
\text { companies, government and citizens. Sustainability features commonly involve sustainable } \\
\text { 'living, working and mobility' [8]. [7] define urban living labs as being closely aligned to local } \\
\text { government, and with a strong focus on value creation and civic engagement. }\end{array}$ \\
\hline $\begin{array}{l}\text { Citizens' } \\
\text { Dashboard }\end{array}$ & $\begin{array}{l}\text { A citizens' dashboard is an interactive 'app' located on a mobile phone, tablet, laptop or PC } \\
\text { providing opportunities for citizens and businesses to co-create by commenting on urban } \\
\text { problems or sustainability issues, and which makes available public information sources, } \\
\text { such as traffic congestion, air quality, routes for walking/cycling, open data sources, and } \\
\text { online connectivity [91]. Citizens' dashboards can be used to access key performance } \\
\text { information from open data, allowing for detailed analysis [44]. }\end{array}$ \\
\hline
\end{tabular}




\begin{tabular}{|c|c|}
\hline Gamification & $\begin{array}{l}\text { Incentivisation of citizens to participate in co-production as a means of providing solutions } \\
\text { to urban problems, is increasingly taking place through gamification of public services, by } \\
\text { tapping in to the apparently growing use of gamification technologies in people's everyday } \\
\text { lives. The citizen may assume an 'identity' and might be 'ranked' according to the amount } \\
\text { of activity which they generate [5]. Gamification might also be used to improve the skillsets } \\
\text { of citizens to allow them to participate more effectively [21]. }\end{array}$ \\
\hline $\begin{array}{l}\text { 'Open' } \\
\text { Datasets }\end{array}$ & $\begin{array}{l}\text { 'Open' data, often referred to erroneously as 'big data' [20], involves making datasets } \\
\text { publicly available, which contain anonymised statistical, performance, or demographic } \\
\text { information generated by public bodies, relating for example to employment, housing, } \\
\text { health, education, welfare, crime, transport, or simply the provision of services. In the UK, } \\
\text { 'open' data is provided by, amongst others, local and central government; government } \\
\text { ministers; fire and police boards; national park authorities [82]. }\end{array}$ \\
\hline Crowdsourcing & $\begin{array}{l}\text { Crowdsourcing is a Web-based engagement model which collects the online views of } \\
\text { citizens (the 'crowd') in relation to a particular social issue, such as a public planning issue } \\
\text { [16], or proposals by a municipality perhaps to engage in a particular activity or potential } \\
\text { investment, e.g. cycling infrastructure investment [6]. Specific groups can be targeted, or } \\
\text { the invitation to engage and participate can be completely open. Crowdfunding, designed } \\
\text { to generate financial resources, is an example of crowdsourcing. }\end{array}$ \\
\hline
\end{tabular}




\section{Figure 1: Technologically-mediated Municipal Reciprocity}

\section{Municipality Inputs}

Shared sustainability targets with citizenry

Devolved power to communities, including 'hard to reach' groups

Improved communication with citizens using new ICTs Incentivisation of citizens using new ICTs

Creative use of social media and open data

Defined benefits to citizens through participation in Smart governance.
Promised Reciprocity Outcomes

Smart city governance

Empowered and participating (including disadvantaged) communities

Shared sustainability successes, reduced $\mathrm{CO} 2$ levels

Improved digital literacy, and shared learning

Community use of reclaimed spaces (urban gyms, allotments, public artwork) Improved quality of life: happier citizens?

Co-produced informational relationships and activities

\section{Citizen Inputs}

Trust in municipality

Learning new ICT skills, including how to access and interpret open data.

Shared learning amongst communities, through use of ICTs

Community leadership

Shared sustainability values with other citizens and the municipality

Active citizenship and eParticipation in local affairs and decision-making.

CONTEXTUAL ENVIRONMENT: Institutions, culture, technologies and practices 